\title{
Radiographic and Histological Analysis of a Synthetic Bone Graft Substitute Eluting Gentamicin in the Treatment of Chronic Osteomyelitis
}

\author{
Jamie Ferguson ${ }^{\boxplus}$, Nicholas Athanasou ${ }^{2}$, Michael Diefenbeck ${ }^{3}$, Martin McNally ${ }^{4}$ \\ 1. Consultant in Limb Reconstruction and Trauma Surgery, Bone Infection Unit, Nuffield Orthopaedic Centre, Oxford University Hospitals NHS Foundation \\ Trust, Oxford, UK \\ 2. Professor of Musculoskeletal Pathology, Bone Infection Unit, Nuffield Orthopaedic Centre, Oxford University Hospitals NHS Foundation Trust, Oxford, \\ UK \\ 3. Honorary Consultant Orthopaedic Surgeon, Oxford University Hospitals NHS Foundation Trust, Oxford, UK \\ 4. Consultant in Limb Reconstruction Surgery, Honorary Senior Lecturer in Orthopaedic Surgery, Bone Infection Unit, Nuffield Orthopaedic Centre, Oxford \\ Radcliffe Hospitals NHS Foundation Trust, Oxford, UK \\ $\square$ Corresponding author: Jamie Ferguson, email: jamieferguson@doctors.org.uk
}

(c) Ivyspring International Publisher. This is an open access article distributed under the terms of the Creative Commons Attribution (CC BY-NC) license (https://creativecommons.org/licenses/by-nc/4.0/). See http://ivyspring.com/terms for full terms and conditions.

Received: 2018.11.17; Accepted: 2019.02.09; Published: 2019.03.16

\begin{abstract}
Introduction: Managing chronic osteomyelitis can be challenging and attention to the osseous dead-space left following resection is an important part of successful treatment. We assess radiographic bone healing following implantation of a gentamicin-eluting synthetic bone graft substitute (gBGS) used at chronic osteomyelitis (cOM) resection. We also describe histological carrier changes from biopsies in nine cases at various time points.

Methods: This was a retrospective review of a prospectively collected consecutive series of 163 patients with Cierny-Mader Type III or IV cOM who underwent single-stage excision, insertion of gBGS and definitive soft-tissue closure or coverage. Bone defect filling was assessed radiographically using serial radiographs. Nine patients had subsequent surgery, not related to infection recurrence, allowing opportunistic biopsy between 19 days and two years after implantation.

Results: Infection was eradicated in $95.7 \%$ with a single procedure. 138 patients had adequate radiographs for assessment with minimum one-year follow-up (mean 1.7 years, range 1.0-4.7 years). Mean void-filling at final follow-up was $73.8 \%$. There was significantly higher void-filling in metaphyseal compared to diaphyseal voids (mean $79.0 \%$ versus $65.6 \% ; p=0.017$ ) and in cases with good initial interdigitation of the carrier (mean $77.3 \%$ versus $68.7 \% ; p=0.021$ ). Bone formation continued for more than two years in almost two-thirds of patients studied $(24 / 38 ; 63.2 \%)$.

Histology revealed active biomaterial remodelling. It was osteoconductive with osteoblast recruitment, leading to the formation of osteoid, then woven and lamellar bone on the substrate's surface. Immunohistochemistry demonstrated osteocyte specific markers, dentine matrix protein-1 and podoplanin within the newly formed bone.

Conclusion: This antibiotic-loaded biomaterial is effective in managing dead-space in surgically treated cOM with a low infection recurrence rate $(4.3 \%)$ and good mean bone void-filling $(73.8 \%)$. The radiographic resolution of the bone defect is associated with bone formation, as supported by histological analysis.
\end{abstract}

Key words: osteomyelitis, radiology, histology, bone graft substitute, treatment, outcome

\section{Introduction}

Dead-space management is a key element in successfully treating chronic osteomyelitis. Any bone void remaining following resection will fill with haematoma or fluid, which provides a poorly vascularised environment conducive for residual organisms to proliferate, potentially leading to infection recurrence [1]. Furthermore, any unhealed bone void is a potential weakness that risks a later 
fracture [2].

Local antibiotics have been used in residual bone voids in an effort to reduce infection recurrence rates. Traditionally antibiotics have been added to polymethylmethacrylate (PMMA) [3]. More recently antibiotics have been combined with biodegradable carriers, thus avoiding the need for the carrier's later removal and allowing the potential for host bone healing [4].

The ideal local antibiotic carrier would elute high initial antibiotic levels then dissolve, providing an osteoconductive scaffold for bone healing. The first biodegradable material used to fill bone voids was calcium sulphate (CS), described by Dressmann in 1892 [5]. In 1959 Peltier investigated radiographic bone defect filling with CS in animal models, concluding that CS resorbed completely but quickly, leading to incomplete bone healing [6]. His studies were the starting point for the radiographic descriptions following the use of bone graft substitute (BGS) [7]. Our own experience with tobramycin containing CS demonstrated disappointing bone healing [8].

Other materials, such as tricalcium phosphate (TCP), have been used as void fillers in distal radius and tibial plateau fractures [9-11]. However, in clinical follow-up radiographs TCP demonstrates almost no resorption or remodelling, still being present relatively unchanged at 30 months in tibia plateau fractures [11]. This risks reinfection of the material, foreign body reaction, or fatigue failure due to the prevention of bone ingrowth [4].

A potential solution to optimising dissolution rates might be combining differing carrier types into one formulation, allowing multiple phases of resorption. A faster resorbing component, such as CS, can dissolve quickly, allowing early release of high antibiotic levels, leaving behind a slower dissolving porous scaffold, offering more prolonged structural stability and bone ingrowth. CERAMENT ${ }^{\circledR} \mid$ Bone void filler (BONESUPPORT AB, Lund, Sweden) contains $60 \mathrm{wt} \%$ calcium sulphate hemihydrate and $40 \mathrm{wt} \%$ sintered hydroxyapatite [12-13]. Its use in distal radial opening wedge osteotomies for malunions [14], tibial plateau fractures [15] and bone cysts [16] have demonstrated BGS resorption and new bone formation.

With the addition of $17.5 \mathrm{mg} / \mathrm{ml}$ of gentamicin, CERAMENT $^{\circledR} \mid \mathrm{G}$ (BONESUPPORT AB, Lund, Sweden) was first evaluated in a rat osteomyelitis model, demonstrating improved bone healing [17]. The local in vitro antibiotic elution is very high; 100-1000 times greater than the Minimum Inhibitory Concentrations of organisms in a cohort of osteomyelitis cases [18]. More recently good clinical results were published when used to treat $\mathrm{COM}$ in a prospective cohort study of 100 patients [19].

Histological data following BGS implantation is relatively sparse, mainly derived from tumour cases after resection of possible recurrent tumour [20-22]. Little histological data is available for BGS used for trauma defects due to concerns that fracture biopsy might result in new bone voids or instability [23]. Data is absent in the management of infected bone defects.

The primary aim of this follow on study is to assess the radiographic bone void healing seen a minimum of one year following implantation of this gentamicin-eluting synthetic bone substitute (gBGS) into bone defects after resection of chronic osteomyelitis (cOM) in a single-stage operation. The secondary outcomes were the clinical outcomes of infection recurrence and fracture rate affecting the treated bone segment. We also report the histological cell and tissue changes in response to the gBGS in a small group of cases in which opportunistic biopsy of the operation site was possible.

\section{Material and Methods}

\section{Inclusion Criteria}

A consecutive series of cases with Cierny-Mader Type III (localised) or Type IV (Diffuse) chronic osteomyelitis treated with a single-stage procedure using CERAMENT ${ }^{\circledast} \mid \mathrm{G}$ was analysed. All cases had confirmed infection, as defined by symptoms for a minimum of six months with clinical and radiographic signs, along with at least one of the following: a draining sinus; an abscess or intra-operative pus; two or more microbiological cultures with indistinguishable microorganism or positive histology [8].

Patients with osteomyelitis secondary to diabetic foot infection were excluded.

Cases with Cierny-Mader Type IV with large segment defects $>1 \mathrm{~cm}$ were also excluded as in our centre these cases are usually treated using Ilizarov frames with distraction osteogenesis. In these cases the dead-space can be obliterated using acute shortening with relengthening at a distant site via a corticotomy or by the use of bone transport techniques $[4,24]$.

Between 2013 and 2017, 196 patients were identified and treated as part of a single-stage protocol (see Figure 1). This series included a previously reported cohort of 100 patients [20]. Thirty-three cases were excluded from analysis as they were treated with a combination of CERAMENT ${ }^{\circledR} \mid \mathrm{G}$ and another calcium sulphate antibiotic carrier. The remaining 163 cases when CERAMENT ${ }^{\circledR} \mid G$ was used in isolation had at least one-year clinical follow-up (mean 21.4 months; 
12-56). These 163 cases were used to report the clinical outcomes. The radiographic outcomes were only reported for cases with a minimum of one-year radiographic follow-up, meaning a further 25 cases were excluded, with 138 cases remaining available for this part of the study.

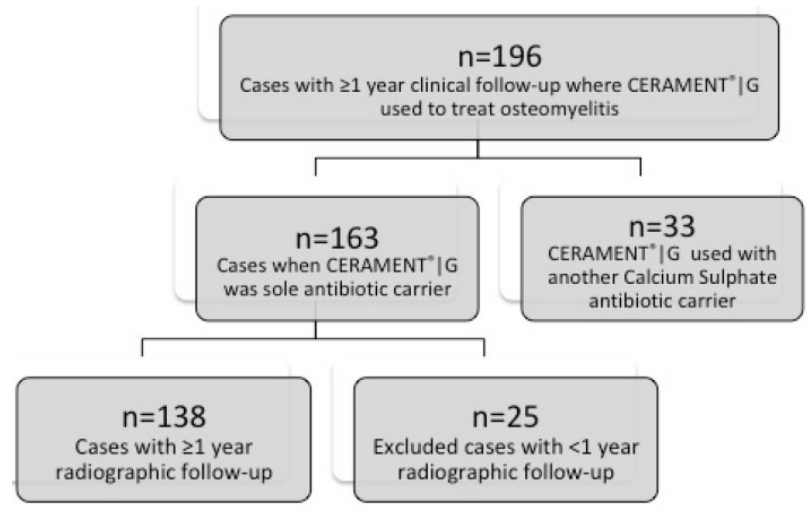

Figure 1. Flowchart demonstrating excluded cases.

\section{Surgical technique}

All patients were treated in a single-stage $[8,19]$. Multiple deep intra-operative samples were taken, using an established protocol [25-27]. Sinus tracts were excised and infected implants removed. Excision continued until healthy, bleeding bone was exposed. After excision, the area was irrigated with $0.05 \%$ aqueous chlorhexidine solution and the cavity dried with gauze packing. The dead-space was filled with CERAMENT $^{\circledR} \mid G$, which is initially liquid and injectable, but hardens over 15-20 minutes, forming a solid mass within the defect. No additional material or antibiotic was added. If instability was present, stabilisation was provided by external or internal fixation. Primary skin closure was achieved either directly or by local or free microvascular muscle flaps.

\section{Antibiotic management}

Antibiotic therapy was stopped at least two weeks prior to surgery, provided it was safe to do so $[8,28]$. During surgery, intravenous vancomycin and meropenem were given following sampling, as this regime was effective against $96 \%$ of the isolated organisms in a previous study [27]. Antibiotic treatment usually continued for 6-12 weeks based on the results of the final culture (mean 10.2 weeks).

\section{Radiographic Assessment}

Radiographs of the operated bone were taken immediately post-operative, at six weeks, at three, six and 12 months and yearly thereafter.

The location of the infection was classified as metaphyseal, diaphyseal or combined. The initial post-operative image was examined to delineate the extent of the bone void filled with CERAMENT ${ }^{\circledR} \mid \mathrm{G}$. The bone filling was measured by comparing the initial post-operative image to the latest follow-up radiographs. The AP views were first compared and the percentage of new bone occupying the space that was initially filled by the carrier was measured to the nearest $5 \%$. Next the same process was undertaken on the lateral image. These two percentage scores for each view were then added together and divided by two to give the final mean percentage void-filling for each case. To check the reliability of these measures $20 \%$ of the cases were randomly selected and the intra-rater reliability was calculated for these observations.

The degree of initial bone/carrier interdigitation was recorded on the immediate post-operative radiograph. Carrier interdigitation was assessed to be either good, if no gap was present between the carrier and bone on any view, or poor, if a gap was evident.

Following our previous study [19], three distinct radiographic features of CERAMENT ${ }^{\circledR} \mid \mathrm{G}$ remodelling were noted in a minority of cases:

- "Halo sign"- A radiopaque hyperdense ring noted around the periphery of the bone void and the gBGS, if present usually appearing on the six-week follow-up radiographs (see Figure 3a).

- "Marble sign" - Marble-shaped hypodense remnant of the biomaterial noticed up to three months after surgery (see Figure 3b). Later resorption of the gBGS occurred and the Marble sign disappeared.

- "Puddle sign" - A hyperdense region of biomaterial accumulating at the bottom of the bone excision site (See Figure 3c). This finding was usually seen between three to six months after implantation.

The relationship between bone void-filling and the degree of initial carrier interdigitation into the surrounding bone, radiographic signs of an extra-osseous leak and the presence or absence of a Halo, Marble or Puddle sign, were also analysed.

\section{Histology}

Nine patients had subsequent surgery, not related to infection recurrence, allowing opportunistic biopsy of the implanted material. The indications for the repeated surgery in the nine cases are listed in Table 3. These biopsies were taken at various different time points, between 19 days and two years following the index procedure, allowing a description of the remodelling of the carrier over time.

Samples were fixed in formalin, routinely processed and stained with haematoxylin-eosin. An 
indirect immunoperoxidase technique was used to perform immunohistochemistry. This allowed the identification of a range of bone cell markers, including: the osteocyte markers Dentine Matrix Protein-1 and Podoplanin, the macrophage/osteoclast marker CD68, and the macrophage marker CD14 [29-31].

Table 1. Location of Chronic Osteomyelitis treated in each case.

\begin{tabular}{lllll}
\hline Bone & Metaphysis & Diaphysis & $\begin{array}{l}\text { Combined } \\
\text { Metaphyseal } \\
\text { Diaphyseal }\end{array}$ & Total \\
\hline Tibia & $41(34)$ & $28(23)$ & 9 & $78(66)$ \\
Femur & $16(14)$ & $12(11)$ & 4 & $32(29)$ \\
Humerus & $15(10)$ & $6(4)$ & 1 & $22(15)$ \\
Radius & 5 & 3 & 1 & 9 \\
Calcaneum & $7(6)$ & & & $7(6)$ \\
Ulna & $1(0)$ & 3 & & $4(3)$ \\
Ankle fusion & 3 & & & 3 \\
Clavicle & 2 & & & 2 \\
Fibula & 2 & & & 2 \\
Foot (Talus) & 1 & & & 1 \\
Pelvis & $2(1)$ & & & $163(138)$ \\
Knee Fusion & 1 & $52(44)$ & & 15 \\
Total & $96(79)$ & & & 16 \\
\hline
\end{tabular}

Numbers in brackets represent the 138 cases with a minimum one-year radiographic follow-up used to assess bone healing.

Table 2. Distribution of Cierny-Mader anatomic type and physiologic classification in the cohort of 154 cases with minimum one-year clinical follow-up.

\begin{tabular}{llll}
\hline & \multicolumn{3}{l}{ Anatomic Type } \\
\cline { 2 - 4 } Physiologic Classification & III Localised & IV Segmental & Total \\
\hline A Normal & $30(27)$ & $5(4)$ & $35(31)$ \\
B L Local Compromise & $38(33)$ & 5 & $43(38)$ \\
B Systemic Compromise & $25(19)$ & $9(7)$ & $34(26)$ \\
B L,S Local and Systemic & $35(29)$ & $16(14)$ & $51(43)$ \\
Compromise & & $35(30)$ & $163(138)$ \\
Total & $128(108)$ & & \\
$\begin{array}{l}\text { The numbers in brackets represent the 138 cases with adequate radiographs at a } \\
\text { minimum of one year. }\end{array}$
\end{tabular}

Table 3. Details of cases in which a biopsy of the CERAMENT ${ }^{\circledR} \mid G$ was performed.

\begin{tabular}{|c|c|c|}
\hline $\begin{array}{l}\text { Bone } \\
\text { involved }\end{array}$ & $\begin{array}{l}\text { Time from } \\
\text { index } \\
\text { procedure }\end{array}$ & Indication for surgery allowing biopsy \\
\hline Tibia & 19 days & Revision of free flap \\
\hline Calcaneum & 2 months & $\begin{array}{l}\text { Separate area of infection at site distant from } \\
\text { initial surgery requiring excision }\end{array}$ \\
\hline Femur & 4.5 months & $\begin{array}{l}\text { Longstanding below knee amputation. Problems } \\
\text { with prosthetic fitting and resultant tibial } \\
\text { ulceration resulting in patient's request for } \\
\text { conversion to above knee amputation. }\end{array}$ \\
\hline Femur & 5.3 months & Proximal femoral replacement for fracture \\
\hline Tibia & 7.5 months & Below knee amputation for non-union \\
\hline Humerus & 10.0 months & Internal fixation of non-union \\
\hline Tibia & 11.5 months & $\begin{array}{l}\text { Bone grafting of adjacent site due to ongoing } \\
\text { pain }\end{array}$ \\
\hline Tibia & 12.0 months & $\begin{array}{l}\text { Excision of extraosseous carrier material } \\
\text { posterior to distal tibia }\end{array}$ \\
\hline Tibia & 24.1 months & Ilizarov correction of tibial deformity \\
\hline
\end{tabular}

\section{Outcome Measures}

The primary outcome measure was the percentage bone void healing at least one year following surgery. Final void healing was also correlated with the infection location, the degree of initial bone filling and the presence of any radiographic extraosseous leak.

The secondary outcome measures were infection recurrence rate, subsequent fracture involving the treated segment and histological descriptions of specimens taken opportunistically at varying time points following implantation in the nine cases described above. Infection recurrence was defined as positive cultures from further radiologically guided aspiration or biopsy; recurrent sinus formation; further surgery performed for infection; or any patient requiring antibiotic treatment for persisting symptoms.

\section{Statistical Analysis}

All data were considered to be non-parametric. Associations between categorical variables were made using Fisher's exact test. Continuous variables were compared using a Mann-Whitney $U$ test for two groups. Relationships between continuous variables were investigated using Spearman's Rank Correlation. A p-value of $<0.05$ was considered statistically significant. The intra-observer variability for radiographic measurements was calculated using the Cohen's weighted Kappa score.

\section{Results}

There were 109 males and 54 females, with a mean age 51.6 years old (range 17.8-86.1). The aetiology and microbiology of the cases is demonstrated in Table 4 . The mean defect size following excision was $10.9 \mathrm{~cm}^{3}$ (range $1-30 \mathrm{~cm}^{3}$ ).

Osseous fixation was undertaken in 31 cases; 14 Ilizarov frames, 13 monolateral frames, two intramedullary nails and two plate fixations. Fifty cases required soft-tissue cover performed by plastic surgeons (24 free gracilis flaps, 12 free latissimus dorsi flaps, one free ALT flap, nine local gastrocnemius flaps, one local vastus lateralis muscle flap and three local fasciocutaneous flaps).

\section{Radiographic Outcomes}

In the 138 cases with a minimum one-year radiographic follow-up (mean 1.7 years, range 1-4.7 years) the bone defect was metaphyseal in 79, diaphyseal in 44, and combined in 15 patients. Cohen's weighted Kappa score for intra-observer reliability was 0.771 (standard error $=0.0386,95 \% \mathrm{CI}=$ 0.6954 to 0.8466 ), suggesting substantial agreement in measurements. 
The mean void-filling at final follow-up was $73.8 \%$ (range $0-100 \%$ ) and was significantly higher in metaphyseal lesions $(79.0 \%)$ compared to diaphyseal lesions $(65.6 \%)(p=0.017)$ (see Figure 2). Complete void-filling, with disappearance of the defect at final follow-up, was seen in 34 cases (24.6\%). Only 18 cases $(13.0 \%)$ had less than $50 \%$ void-filling at final follow-up.

If there was good initial interdigitation of the carrier and bone on the immediate post-operative radiograph there was significantly better bone healing at final follow-up (77.3\% filling vs. $68.7 \% \mathrm{p}=0.02088)$. The volume of the defect was not found to significantly affect the degree of bone healing seen at final follow-up $\left(\mathrm{r}_{\mathrm{s}}=-0.11914, \mathrm{p}=0.164\right)$.

Bone formation progressed between the first and second years of follow-up in $63.2 \%$ of the 38 cases with more than two years follow-up.

During radiographic follow-up 58/138 (42.0\%) had at least one feature of CERAMENT $^{\circledR} \mid \mathrm{G}$ remodelling (Halo, Marble or Puddle sign), 30/138 $(21.7 \%)$ had at least two and 13/138 (9.4\%) had all three. These three features were significantly more likely to be seen in metaphyseal defects compared to diaphyseal defects (Halo; $\mathrm{p}=0.0479$, Marble; $\mathrm{p}=0.0253$, Puddle; $p=0.0201$ ) (see Table 5).

In 26 patients, there was radiographic evidence of material leak out of the bone into the surrounding tissues (extraosseus leak). The mean void-filling at final follow-up was significantly lower when there was evidence of an early extraosseous leak on radiographs; $62.1 \%$ versus $76.5 \%(\mathrm{p}=0.0063)$ (see Table 6). The mean filling was also significantly lower in cases when a Marble sign $(58.4 \%$ versus $77.2 \%$, $p=0.00028)$ or Puddle sign $(64.5 \%$ versus $76.3 \%$, $\mathrm{p}=0.033$ ) were present during follow-up, though not for Halo sign $(68.9 \%$ versus $76.3 \%, p=0.12)$. There was a significant correlation between the presence of an extraosseous leak on follow-up radiograph and the presence of a Marble sign $(\mathrm{p}=0.015)$, but not for Halo $(\mathrm{p}=0.60)$ or Puddle signs $(\mathrm{p}=0.18)$.

\section{Clinical Outcomes}

Seven of the 163 cases had infection recurrence $(4.3 \%)$, occurring between 0.2-2.1 years after surgery. Recurrence was not significantly higher in CM IV disease or when plastic surgical soft-tissue was used ( $\mathrm{p}=0.3477$ and $\mathrm{p}=0.4397$ respectively).

Calcaneal osteomyelitis was associated with a higher risk of recurrence $(2 / 6$ cases compared to $5 / 132, \mathrm{p}=0.0302$ ).

Isolation of a gentamicin resistant organism at index surgery was not associated with an increased risk of subsequent recurrence $(p=1.0)$. Five out of seven of the cases with recurrence grew a sensitive
Staphylococcus aureus, one case had a negative culture but histology supportive of infection and the remaining case growing the same gentamicin resistant Pseudomonas species encountered in the index procedure.

The overall fracture rate was 4/163 (2.5\%) (mean time from surgery 27.5 weeks (range $0.5-13$ months)). Three cases occurred due to high-energy injuries and one case had a stress fracture of the proximal femur in an area of previous radiotherapy at 13 months, requiring proximal femoral replacement.

Table 4. The aetiology of infection and the microbiological results.

\begin{tabular}{llllll}
\hline Organism & Total & $\begin{array}{l}\text { Fracture } \\
\text { related } \\
\text { infection }\end{array}$ & $\begin{array}{l}\text { Haemato } \\
\text { genous }\end{array}$ & $\begin{array}{l}\text { Infection } \\
\text { following } \\
\text { elective } \\
\text { surgery }\end{array}$ & $\begin{array}{l}\text { Soft- } \\
\text { tissue } \\
\text { injury }\end{array}$ \\
\hline Polymicrobial & $\mathbf{2 9}$ & 19 & 2 & 5 & 3 \\
No growth & $\mathbf{5 9}$ & 37 & 18 & 3 & 1 \\
Monomicrobial & $\mathbf{7 5}$ & 46 & 16 & 11 & 2 \\
MSSA & $\mathbf{4 2}$ & 22 & 12 & 7 & 1 \\
MRSA & $\mathbf{4}$ & 3 & 1 & & \\
CoNS & $\mathbf{3}$ & 3 & & & \\
Pseudomonas spp. & $\mathbf{6}$ & 5 & & 1 & \\
Enterobacter cloacae & $\mathbf{4}$ & 3 & & 1 & \\
Corynebacterium Straitum & $\mathbf{3}$ & 2 & & 1 & \\
Streptococcus spp. & $\mathbf{2}$ & 2 & & & \\
Bacillus spp. & $\mathbf{2}$ & 1 & & 1 & \\
Serratia Marcescens & $\mathbf{2}$ & 2 & & & \\
Achromobacter spp. & $\mathbf{2}$ & 1 & & & \\
Salmonella enteritidis & $\mathbf{1}$ & & 1 & & \\
Proteus mirabilis & $\mathbf{1}$ & 1 & & & \\
Clostridium Difficile & $\mathbf{1}$ & 1 & & & \\
Cutibacterium acnes & $\mathbf{1}$ & & 1 & & \\
Mycobacterium tuberculosis & $\mathbf{1}$ & & 1 & & \\
& $\mathbf{1 6 3}$ & 102 & 36 & & \\
\hline & & & & & \\
\hline
\end{tabular}

Table 5. Distribution of specific features of CERAMENT ${ }^{\circledR} / G$ remodelling across different locations in the bone.

\begin{tabular}{llll}
\hline Feature & $\begin{array}{l}\text { Metaphysis } \\
(\mathbf{n}=\mathbf{7 9})\end{array}$ & $\begin{array}{l}\text { Diaphysis } \\
(\mathbf{n}=\mathbf{4 4})\end{array}$ & $\begin{array}{l}\text { Combined Metaphysis/ } \\
\text { Diaphysis }(\mathbf{n}=\mathbf{1 5})\end{array}$ \\
\hline Halo Sign & $\begin{array}{l}33(41.8 \%) \\
\mathbf{p}=\mathbf{0 . 0 2 3}\end{array}$ & $10(22.7 \%)$ & $4(26.7 \%)$ \\
Marble Sign & $\begin{array}{l}19(24.1 \%) \\
\mathbf{p}=\mathbf{0 . 0 1 3}\end{array}$ & $3(6.8 \%)$ & $3(20.0 \%)$ \\
Puddle Sign & $\begin{array}{l}22(27.8 \%) \\
\mathbf{p}=\mathbf{0 . 0 1 1}\end{array}$ & $4(9.1 \%)$ & $3(20.0 \%)$ \\
\hline
\end{tabular}

There is a significantly higher frequency of these features in the metaphysis compared to the diaphysis.

Table 6. Mean percentage bone void-filling at final follow-up when compared to the presence or absence of various factors.

\begin{tabular}{llll}
\hline Feature & $\begin{array}{l}\text { Feature Present } \\
\text { Number of cases } \\
\text { Mean \% bone } \\
\text { void-filling }\end{array}$ & $\begin{array}{l}\text { Feature Absent } \\
\text { Number of cases } \\
\text { Mean \% bone } \\
\text { void-filling }\end{array}$ & $\begin{array}{l}\mathbf{P} \\
\text { Value }\end{array}$ \\
\hline $\begin{array}{l}\text { Radiographic } \\
\text { Extraosseous leak } \\
\text { Good initial }\end{array}$ & $\mathrm{n}=26,62.1 \%$ & $\mathrm{n}=112,76.5 \%$ & $\mathbf{0 . 0 0 6 3 4}$ \\
$\begin{array}{l}\text { CERAMENT®|G } \\
\text { Interdigitation }\end{array}$ & $\mathrm{n}=82,77.3 \%$ & $\mathrm{n}=56,68.7 \%$ & $\mathbf{0 . 0 2 0 8 8}$ \\
Halo Sign & $\mathrm{n}=47,68.9 \%$ & $\mathrm{n}=91,76.3 \%$ & 0.12356 \\
\hline
\end{tabular}




\begin{tabular}{llll}
\hline Marble Sign & $\mathrm{n}=25,58.4 \%$ & $\mathrm{n}=113,77.2 \%$ & $\mathbf{0 . 0 0 0 2 8}$ \\
Puddle Sign & $\mathrm{n}=29,64.5 \%$ & $\mathrm{n}=109,76.3 \%$ & $\mathbf{0 . 0 3 3 1 8}$ \\
\hline
\end{tabular}
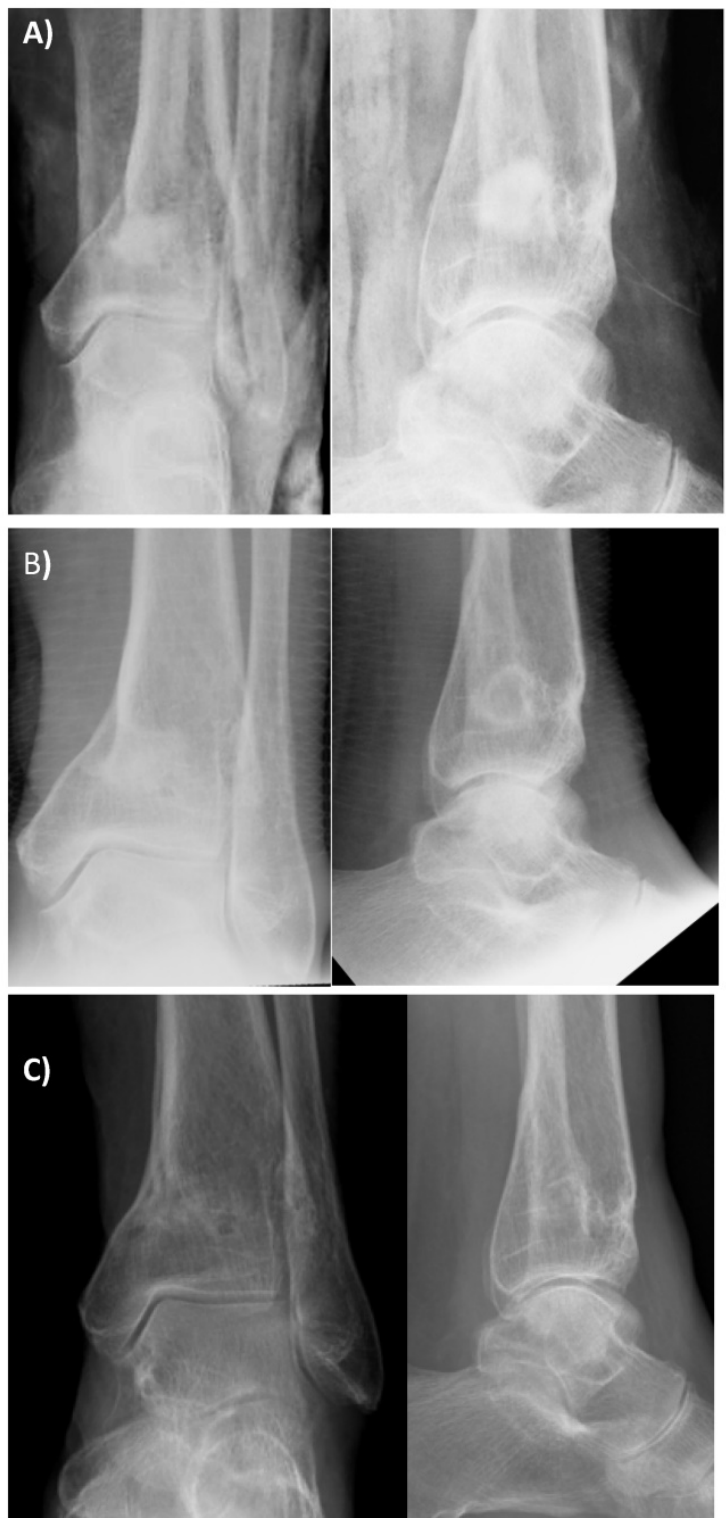

Figure 2. (A) Immediate post-operative follow-up radiographs (AP and lateral view) after debridement and filling of an osteomyelitic bone defect of the distal tibia. (B) Follow-up radiographs (AP and lateral view) six weeks following surgery. Note "Halo sign" in lateral view at six weeks. (C) Images taken 12 months following surgery. There is almost complete filling of the void with new bone.

\section{Histology}

Regarding the nine biopsies studied, the defect contained necrotic tissue and gBSG particles to which there was a prominent (CD14+/ CD68+) macrophage response. Around the defect macrophages were also present in reparative cellular and collagenous fibrous tissue, which showed a variable degree of vascularity.

In early biopsies (19 days and 2 months), there were focal areas where osteoblastic cells covered gBSG particles with an osteoid-like matrix (Figure 4a).
There was focal mineralisation of the osteoid matrix and early woven bone formation (Figure 4b). Osteoid/bone formation was most prominent in areas of well-vascularised fibrous tissue. Osteocytes in woven bone expressed the osteocyte markers dentine matrix protein-1 (DMP-1) and podoplanin (Figure 4c). No cartilage or endochondral ossification was noted.

In biopsies taken four to five months following carrier insertion, more evidence of bone formation was noted with trabeculae that contained gBSG particles. The bone formed was mainly woven but partly lamellar in type. There were numerous (CD14+/ CD68+) macrophage-like mononuclear cells with plump cytoplasm and multinucleated giant cells, both of which contained gBSG particles. Giant cells on the surface of newly formed mineralised osteoid and woven bone expressed an osteoclast phenotype (CD68+/CD14-).

In later biopsies (up to two years), there were increased numbers of larger bone trabeculae within well-vascularised reparative fibrous tissue containing gBSG particles; bone trabeculae formed were composed of woven and lamellar bone although more lamellar bone was seen in biopsies $>5$ months after carrier insertion (Figure 4d). gBSG particles were often incorporated into formed lamellar and woven bone trabeculae. In poorly vascularised areas containing gBSG, principally at the centre of the filled void, there was no osteoid/new bone formation. Surrounding both the void and covering reparative fibrous tissue containing gBSG-associated newly formed bone, there was prominent reactive host cancellous bone.

In one case the biopsy was taken from an extraosseous lump posterior to the distal tibia that had failed to resolve after an extraosseous leak of material. This was the only case that required reoperation for extraosseous leak. In the other 25 cases some degree of leak was noted on follow-up radiographs but these fully resolved in all cases. The histology in this case showed a heavy macrophage infiltrate in response to the material, but notably no evidence of osteoid or bone formation in relation to the material or in surrounding soft-tissues.

\section{Discussion}

Radiographic evidence of bone defect healing was good, with almost a quarter of cases demonstrating full void-filling at final follow-up $(24.6 \%)$. In contrast another study examining void-filling with a pure CS carrier in osteomyelitis demonstrated no filling of the defect in $36.6 \%$, partial filling in $59.0 \%$ and complete filling in only $4.4 \%$ [8].

In our study, no patient required bone grafting of the defect and the gBGS promoted sufficient bone 
formation, resulting in a low fracture rate $(2.5 \%)$.

Other studies have reported higher fractures rates

$(4-14 \%)$ in defects after surgery for cOM $[4,8,32,33]$.

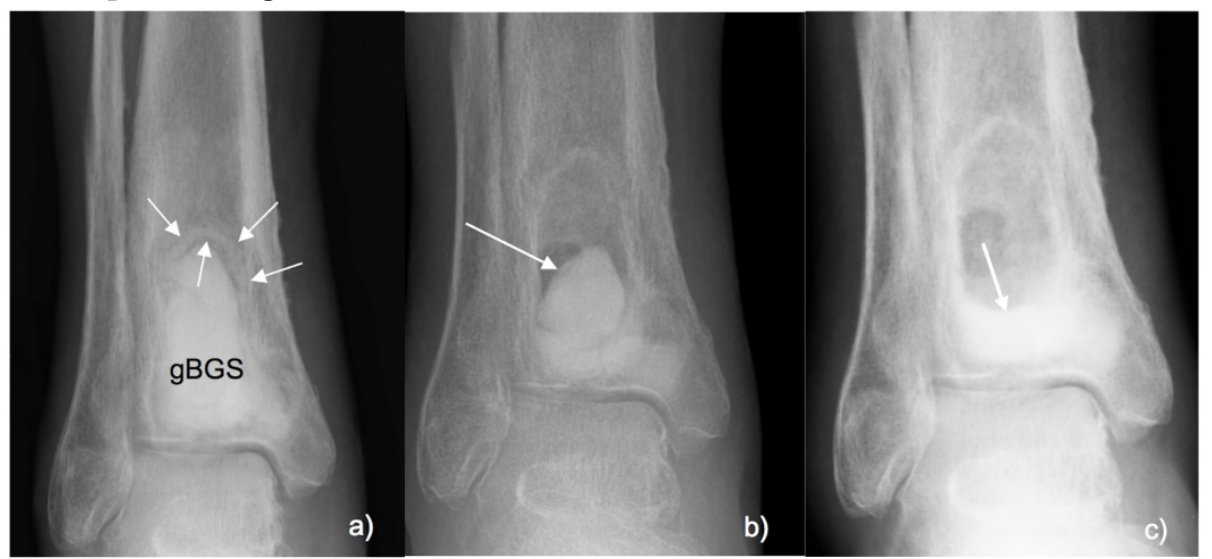

Figure 3. (A) AP radiograph 6 weeks after debridement and filling of an osteomyelitic bone void in the distal tibia. Halo sign: Radio-dense ring around the gBGS (arrows). (B) Marble sign noted at 12 weeks with remnant of the biocomposite appears in the bone void (arrow). (C) Puddle sign at 26 weeks with remnants of the biocomposite accumulating at the bottom of bone void (arrow).
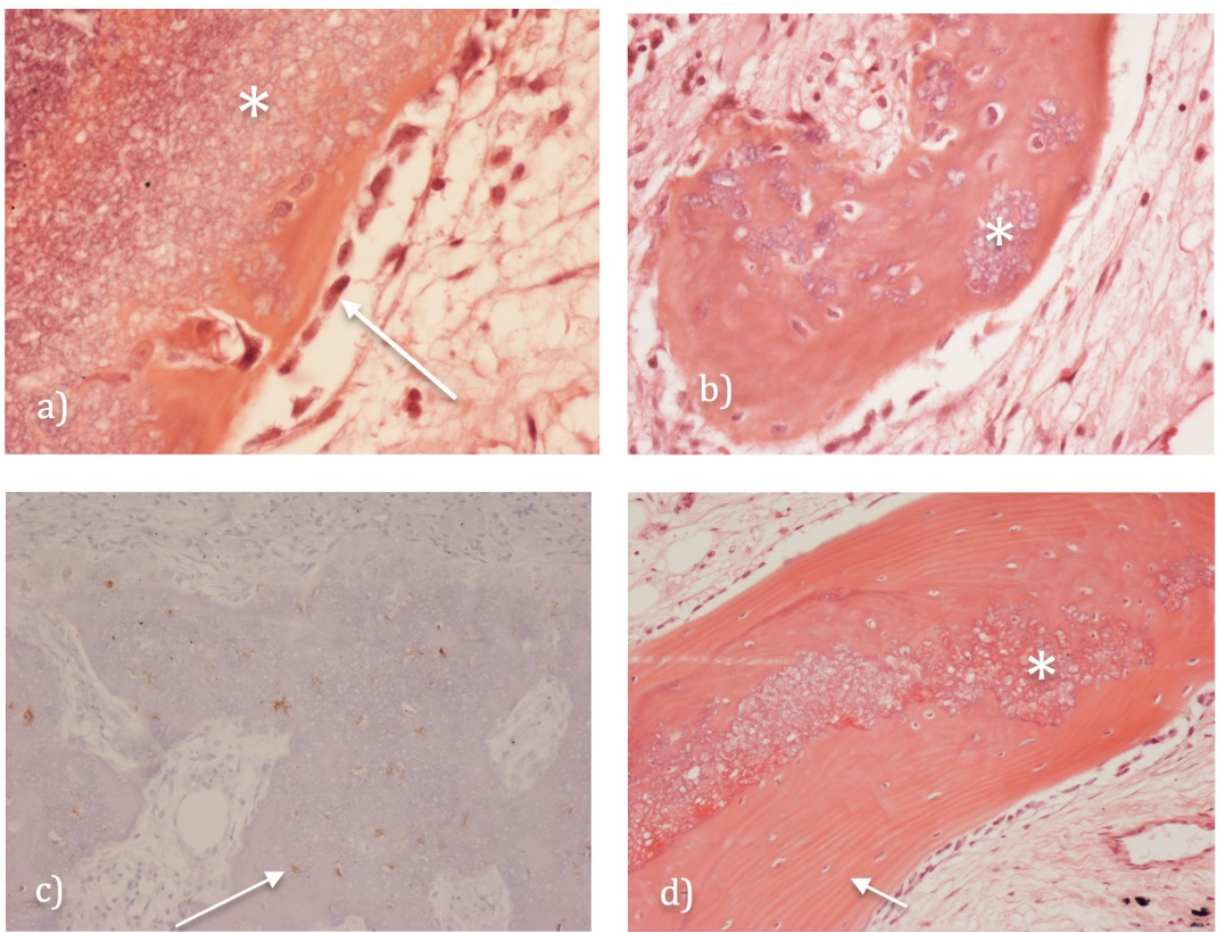

Figure 4. Histology of CERAMENT®|G (A) an early biopsy showing CERAMENT®|G (see asterisk) covered by an osteoid-like matrix produced by osteoblastic cells seen lining the gBGS surface (see arrow). (B) shows focal mineralisation of the osteoid matrix and early woven bone formation around the residual gBGS (see asterisk). (C) immunohistochemistry demonstrating osteocytes in woven bone (brown staining) around the gBGS, expressing dentine matrix protein-1 (DMP-1) and podoplanin (see arrow). (D) later biopsy (at 2 years) demonstrating BSG particles (see asterick) incorporated into formed lamellar bone trabeculae (see arrow).

The infection recurrence rate of $4.3 \%$ with a single operation is low, particularly as the series includes many patients with associated medical comorbidities (78.5\% Cierny-Mader Type B hosts) and $21.5 \%$ with segmental involvement (Cierny-Mader Type IV). In previous studies, these features were associated with higher recurrence rates of up to $27 \%$ $[33,34]$. Published cohorts treated with other substitutes (bioglass, CS, PMMA or antibiotic-loaded bone) have reported higher recurrence rates $(9-37.5 \%)$, with similar follow-up $[8,32,33,36-40]$.

Histology of the biopsied cases correlated well with the radiological finding of progressive voidfilling. Whilst direct comparisons between the radiographic and histological elements of the study are not possible, the histology findings do suggest that radiographic changes were due to bone formation and not due to residual radiodense gBGS. 
There was clear evidence of the gBSG being osteoconductive with first osteoid then woven and lamellar bone being formed. DMP-1- and podoplaninexpressing osteocytes were present in formed woven and lamellar bone and there was evidence of osteoclastic bone remodelling. An increase in lamellar bone was noted in later samples and bone formation was most prominent in areas of well-vascularised reparative fibrous tissue. There was on-going remodelling of the material for beyond a year. The hydroxyapatite particles in CERAMENT ${ }^{\circledR} \mid \mathrm{G}$ are probably responsible for its high osteoconductivity and potential to be transformed into bone.

The distinct Halo, Marble and Puddle signs, noted in almost half of cases in this series, have not been described before with this material. Kotnis, et al. described chronological radiographic appearance of a calcium sulphate-calcium phosphate matrix mixed with beta-tricalcium phosphate granules following bone tumour resection in 11 patients [41]. Their findings showed some similarities to our own: resorption commenced peripherally with gradual inward progression; complete resorption of the BGS was seen at six months [41,42]. Since the radiographic appearance of BGS are variable and can lead to confusion with recurrent or residual disease [43], it is important to understand the time-dependant changes which are seen during follow-up.

The presence of a Marble or Puddle sign was associated with significantly less bone void-filling at final follow-up. Theoretically, if the carrier volume reduces more quickly, either through faster dissolution or as a result of leakage, then the material may dissociate from the bone interface (forming a marble). This may disrupt the interface and reduce the neovascularisation and osteoblast adhesion seen in our histology samples. Conversely, when there was good initial interdigitation of the material with the bone, there was a significant association with better bone formation and defect filling.

We postulate that in instances where there is good bone formation around the periphery of the carrier, the central portion of the void may not receive sufficient stain to promote further bone formation (Wolff's Law). This may in part explain why some voids did not completely resolve during follow-up, after adequate peripheral bone had formed.

This study has some limitations. Samples for histology were collected from revision surgery unrelated to infection recurrence and not at defined time points. Nevertheless, the radiologic and histological features of CERAMENT ${ }^{\circledR} \mid G$ in humans have not been described until now. Our observations might help to understand the resorption pattern and potential for bone formation in humans. Another limitation is that assessment of bone void-filling was based on radiographs without three-dimensional cross-sectional imaging. A more detailed analysis of the resorption process using CT scans and histology is needed. From an ethical point of view, multiple CT scans or biopsies cannot easily be performed in a human study. However, our study findings are similar to a large animal model in sheep that analysed the resorption pattern of CERAMENT ${ }^{\circledR} \mid \mathrm{G}$ and formation of new bone using radiographs, MRI, $\mu \mathrm{CT}$, Dexa-scan and histology. The bone repair was noted to commence in the periphery and move towards the centre of the void [44].

It would be incorrect to solely attribute the low recurrence rate observed to this carrier. Successful surgery for osteomyelitis relies upon many elements of care being done well; adequately excising avascular material, conscientious and systematic microbiologyical and histological sampling, achieving secure osseous stabilisation and providing robust soft tissue coverage. However, bioabsorbable antibiotic-impregnated materials, such as this, offer good dead-space management and extend the indications for singlestage surgery in chronic osteomyelitis, with reduced hospital stays and a more patient-friendly treatment approach.

Radiographic void-filling was good, potentially reducing fracture rates and avoiding the need for bone grafting. Histological correlation confirmed active remodelling of the gBGS into bone with the detection of osteoid and lamellar bone. Bone formation is affected by the site of the lesion and the adequacy of filling at surgery. It is important to achieve good contact between the bone surface and the biomaterial at operation. Bone formation progresses for at least two years after implantation, in two thirds of patients.

\section{Acknowledgements}

JF - study design, data gathering/analysis, writing and editing the paper; NA -data analysis, writing and editing the paper; MD -writing and editing the paper; MM - study design, data gathering/analysis, editing the paper.

\section{Funding}

There was no external funding received for this study.

\section{Competing Interests}

JF, NA and MM declare no competing interests. MD works as Head of Research \& Development, Medical and Clinical Affairs for Bonesupport AB. 


\section{References}

1. Cierny G, Mader JT, Penninck JJ. The classic: A clinical staging system for adult osteomyelitis. Clinical Orthopaedics \& Related Research 2003;414:7-24.

2. McNally $M$, Nagarajah $K$. Osteomyelitis. Orthopaedics and Trauma 2010;24(6):416-29.

3. Walenkamp GH, Vree TOMB, Van Rens TJ. Gentamicin-PMMA beads: Pharmacokinetic and nephrotoxicological study. Clinical Orthopaedics \& Related Research 1986;205:171-83.

4. Ferguson J, Diefenbeck M, McNally M. Ceramic biocomposites as biodegradable antibiotic carriers in the treatment of bone infections. J Bone Jt Infect 2017;2(1):38-51.

5. Dressmann H. Über Knochenplombierung bei höhlenformigen Defekten des Knochens. Beitr Klin Chir 1892;9:804-810.

6. Peltier LF. The use of plaster of Paris to fill large defects in bone. Am J Surg 1959;97:311-315.

7. Turner TM, Urban RM, Gitelis S, Kuo KN, Andersson GB. Radiographic and histologic assessment of calcium sulfate in experimental animal models and clinical use as a resorbable bone-graft substitute, a bone-graft expander, and a method for local antibiotic delivery: one institution's experience. J Bone Joint Surg Am 2001;83-A Suppl 2(Pt 1):8-18.

8. Ferguson JY, Dudareva M, Riley ND, Stubbs D, Atkins BL, McNally MA. The use of a biodegradable antibiotic-loaded calcium sulphate carrier containing tobramycin for the treatment of chronic osteomyelitis: a series of 195 cases. Bone Joint J. 2014; 96-B: 829-836.

9. Kopylov P, Jonsson K, Thorngren KG, Aspenberg P. Injectable calcium phosphate in the treatment of distal radial fractures. J Hand Surg $\mathrm{Br}$ 1996;21:768-771.

10. Keating JF, Hajducka CL, Harper J. Minimal internal fixation and calcium-phosphate cement in the treatment of fractures of the tibial plateau. A pilot study. J Bone Joint Surg Br 2003;85:68-73.

11. Jubel A, Andermahr J, Mairhofer J, Prokop A, Hahn U, Rehm KE. Use of the injectable bone cement Norian SRS for tibial plateau fractures. Results of a prospective 30-month follow-up study. Orthopäde 2004 Aug;33:919-927.

12. Nilsson M, Wang JS, Wielanek L, Tanner KE, Lidgren L. Biodegradation and biocompatability of a calcium sulphate-hydroxyapatite bone substitute. J Bone Joint Surg Br 2004;86:120-125.

13. Nilsson M, Zheng MH, Tägil M. The composite of hydroxyapatite and calcium sulphate: a review of preclinical evaluation and clinical applications. Expert Rev Med Devices 2013;10:675-684.

14. Abramo A, Geijer M, Kopylov P, Tägil M. Osteotomy of distal radius fracture malunion using a fast remodeling bone substitute consisting of calcium sulphate and calcium phosphate. J Biomed Mater Res B Appl Biomater 2010;92:281-286.

15. Iundusi R, Gasbarra E, D'Arienzo M, Piccioli A, Tarantino U. Augmentation of tibial plateau fractures with an injectable bone substitute: CERAMENTTM. Three year follow-up from a prospective study. BMC Musculoskelet Disord 2015;16:115.

16. Kaczmarczyk J, Sowinski P, Goch M, Katulska K. Complete twelve month bone remodelling with a bi-phasic injectable bone substitute in benign bone tumours: a prospective pilot study. BMC Musculoskel. Disord 2015;16:369.

17. Dvorzhinskiy A, Perino G, Chojnowski R, Van Der Meulen M,Ross F, Bostrom $\mathrm{M}$, Yang X. Cerament bone void filler with gentamicin increases bone formation and decreases detectable infection in a rat model of debrided osteomyelitis. Bone Joint J 2015;97-B, Suppl.16:9.

18. Stravinskas M, Horstmann P, Ferguson J, Hettwer W, Nilsson M, Tarasevicius S Petersen M, McNally M, Lidgren L. Pharmacokinetics of gentamicin eluted from a regenerating bone graft, substitute: In vitro and clinical release studies. Bone Joint Res 2016, Sep;5(9):427-35.

19. McNally MA, Ferguson JY, Lau AC, Diefenbeck M, Scarborough M, Ramsden AJ, Atkins BL. Single-stage treatment of chronic osteomyelitis with a new absorbable, gentamicin-loaded, calcium sulphate/hydroxyapatite biocomposite: a prospective series of 100 cases. Bone Joint J 2016;98(9):1289-96.

20. Yamamoto T, Onga T, Marui T, Mizuno K. Use of hydroxyapatite to fill cavities after excision of benign bone tumours. Clinical results. J Bone Joint Surg Br 2000;82:1117-1120.

21. Matsumine A, Myoui A, Kusuzaki K, Araki N, Seto M, Yoshikawa H, Uchida A. Calcium hydroxyapatite ceramic implants in bone tumour surgery. A long-term follow-up study. J Bone Joint Surg Br 2004;86:719-725.

22. Hattori H, Matsuoka H, Yamamoto K. Radiological and histological analysis of synthetic bone grafts in recurring giant cell tumour of bone: a retrospective study. J Orthop Surg (Hong Kong) 2010;18:63-67.

23. Meyer S, Floerkemeier T, Windhagen H. Histological osseointegration of a calcium phosphate bone substitute material in patients. Biomed Mater Eng 2007;17:347-356.

24. McNally M, Ferguson J, Kugan R, Stubbs D. Ilizarov treatment protocols in the management of infected non-union of the tibia. J Orthop Trauma. 2007 Oct;31 Suppl 5:S47-54.

25. Spangehl MJ, Masri BA, O'Connell JX, Duncan CP. Prospective analysis of preoperative and intraoperative investigations for the diagnosis of infection at the sites of two hundred and two revision total hip arthroplasties. J Bone Joint Surg [Am] 1999;81-A:672-683.

26. Atkins BL, Athanasou N, Deeks JJ, Crook DW, Simpson H, Peto TE, McLardy-Smith P, Berendt AR, OSIRIS Collaborative Study Group. Prospective evaluation of criteria for microbiological diagnosis of prosthetic-joint infection at revision arthroplasty. J Clin Microbiol 1998;36:2932-2939.

27. Sheehy SH, Atkins BA, Bejon P, Byren I, Wyllie D, Athanasou NA, Berendt AR, McNally MA. The microbiology of chronic osteomyelitis: prevalence of resistance to common empirical anti-microbial regimens. J Infect 2010; 60: 338-343.

28. Zimmerli W, Trampuz A, Ochsner PE. Prosthetic-joint infections. N Engl J Med 2004;351:1645-54

29. Kashima TG, Dongre A, Opperman U, Athanasou NA. Dentine matrix protein 1 is a marker of bone-forming tumours. Virchows Archiv 2013;462:583-591.

30. Maggiani F, Forsyth R, Hogendoorn PCW, Krenacs T, Athanasou NA. Immunophenotype of osteoclasts and macrophage polykaryons. J Clin Pathol 2011;64:701-5.

31. Athanasou NA, Quinn J. Immunophenotypic differences between osteoclasts and macrophage polykaryons: immunohistological distinction and implications for osteoclast ontogeny and function. J Clin Pathol 1990;43:997-1004.

32. McKee MD, Wild LM, Schemitsch EH, Waddell JP. The use of an antibiotic-impregnated, osteoconductive, bioabsorbable bone substitute in the treatment of infected long bone defects: Early results of a prospective trial. J Orthop Trauma 2002;16:622-627.

33. McKee MD, Li-Bland EA, Wild LM, Schemitsch EH. A prospective, randomized clinical trial comparing an antibiotic-impregnated bioabsorbable bone substitute with standard antibiotic-impregnated cement beads in the treatment of chronic osteomyelitis and infected nonunion. J Orthop Trauma 2010;24:483-90

34. Cierny G 3rd, DiPasquale D. Treatment of chronic infection. J Am Acad Orthop Surg 2006;14(10 Spec No.):S105-110.

35. Lazzarini L, Mader JT, Calhoun JH. Osteomyelitis in long bones. J Bone Joint Surg [Am] 2004;86:2305-2318

36. Xie Z, Liu X, Jia W, Zhang C, Huang W, Wang J. Treatment of osteomyelitis and repair of bone defect by degradable bioactive borate glass releasing vancomycin. J Control Release 2009;139:118-126.

37. Turner TM, Urban RM, Hall DJ, Chye PC, Segreti J, Gitelis S. Local and systemic levels of tobramycin delivered from calcium sulfate bone graft substitute pellets. Clin Orthop Relat Res 2005;437:97-104.

38. Romanò CL, Logoluso N, Meani E, Romanò D, De Vecchi E, Vassena C, Drago L. A comparative study of the use of bioactive glass $553 \mathrm{P} 4$ and antibiotic-loaded calcium-based bone substitutes in the treatment of chronic osteomyelitis a retrospective comparative study. Bone Joint J 2014;96:845-850.

39. Kanakaris N, Gudipati S, Tosounidis T, Harwood P, Britten S, Giannoudis PV. The treatment of intramedullary osteomyelitis of the femur and tibia using the reamer--irrigator--aspirator system and antibiotic cement rods. Bone Joint J 2014;96:783-8

40. Fleiter N, Walter G, Bösebeck H, Vogt S, Büchner H, Hirschberger W, Hoffmann R. Clinical use and safety of a novel gentamicin-releasing resorbable bone graft substitute in the treatment of osteomyelitis/osteitis. Bone Joint Res 2014;3:223-229.

41. Kotnis NA, Parasu N, Finlay K, Jurriaans E, Ghert M. Chronology of the radiographic appearances of the calcium sulphate-calcium phosphate synthetic bone graft composite following resection of bone tumours--a preliminary study of the normal post-operative appearances. Skeletal Radiol 2011;40:563-570.

42. Tan V, Evaniew N, Finlay K, Jurriaans E, Ghert M, Deheshi B, Parasu N. Chronology of the Radiographic Appearances of the Calcium Sulfate-Calcium Phosphate Synthetic Bone Graft Composite Following Resection of Bone Tumors: A Follow-up Study of Postoperative Appearances. Can Assoc Radiol J 2016;67:21-27.

43. Beaman FD, Bancroft LW, Peterson JJ, Kransdorf MJ, Menke DM, DeOrio JK. Imaging characteristics of bone graft materials. Radiographics 2006;26:373-388.

44. Hettwer W, Horstmann P, Bischoff S, Güllmar D, Reichenbach J, Poh P, van Griensven M, Gras F, Diefenbeck M. Establishment and effects of allograft and synthetic bone graft substitute treatment of a critical size metaphyseal bone defect model in the sheep femur. APMIS. 2019; 127: 53-63 